\title{
Second Harmonic Passive Thermography Generated by Cyclic Loading in Composites
}

William P. Winfree, Joseph N. Zalameda, and Elizabeth Gregory NASA Langley Research Center Hampton, VA 23681

Thermosense: Thermal Infrared Applications XL Orlando, FL April 15-19, 2018 


\section{Outline}

NASA Langley Research Directorate

- Introduction

- Passive Thermography for In Situ Inspection

- Identification of points with large harmonic content in thermal responses

- Modeling

- Phase from Friction Heating

- One Dimensional Series Solution

- Two Dimensional Quadrupole Solution

- Comparison Model Output and Measurements

- Summary 
NASA Langley Research Directorate

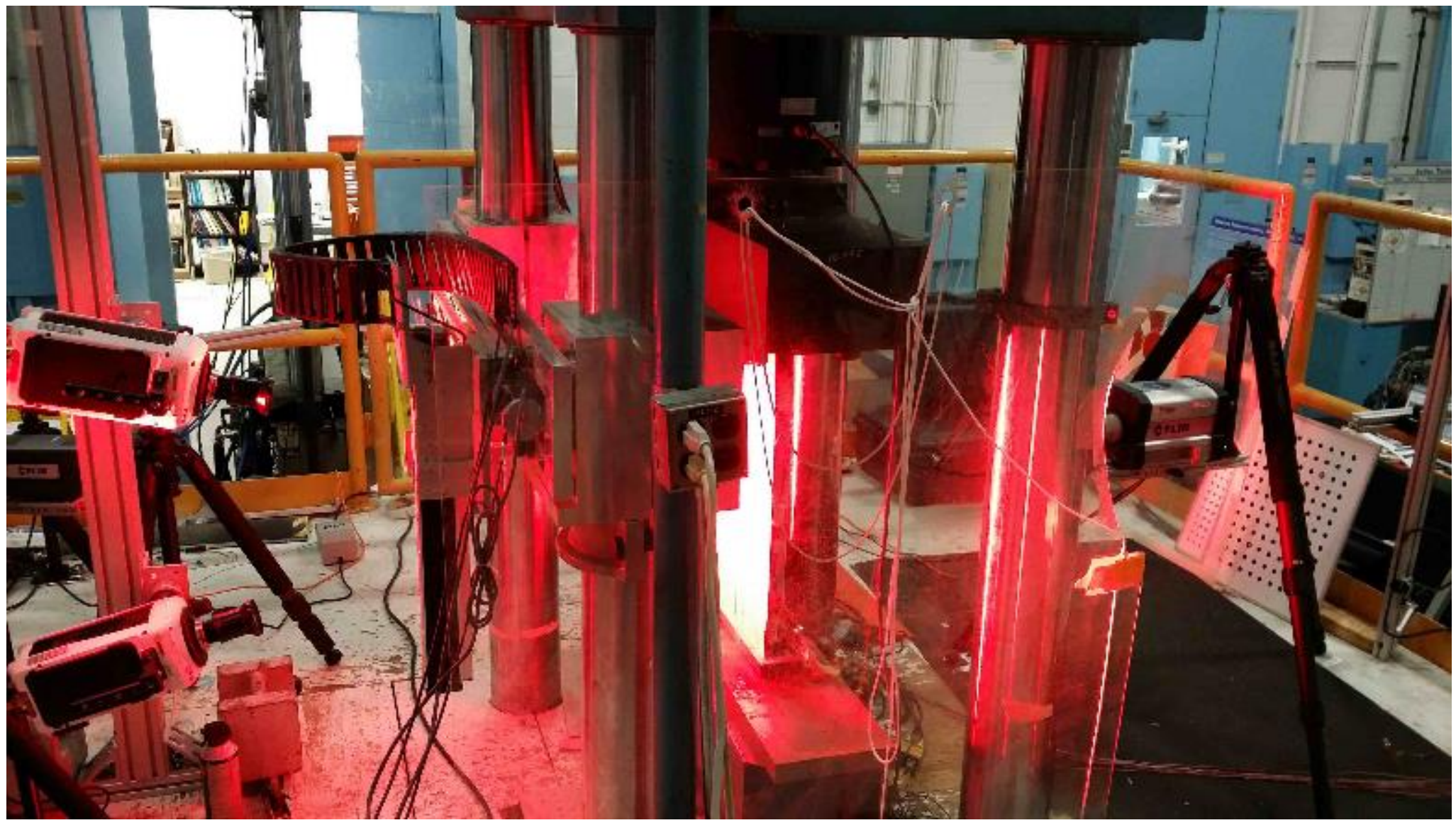




\section{Passive Thermography}

NASA Langley Research Directorate

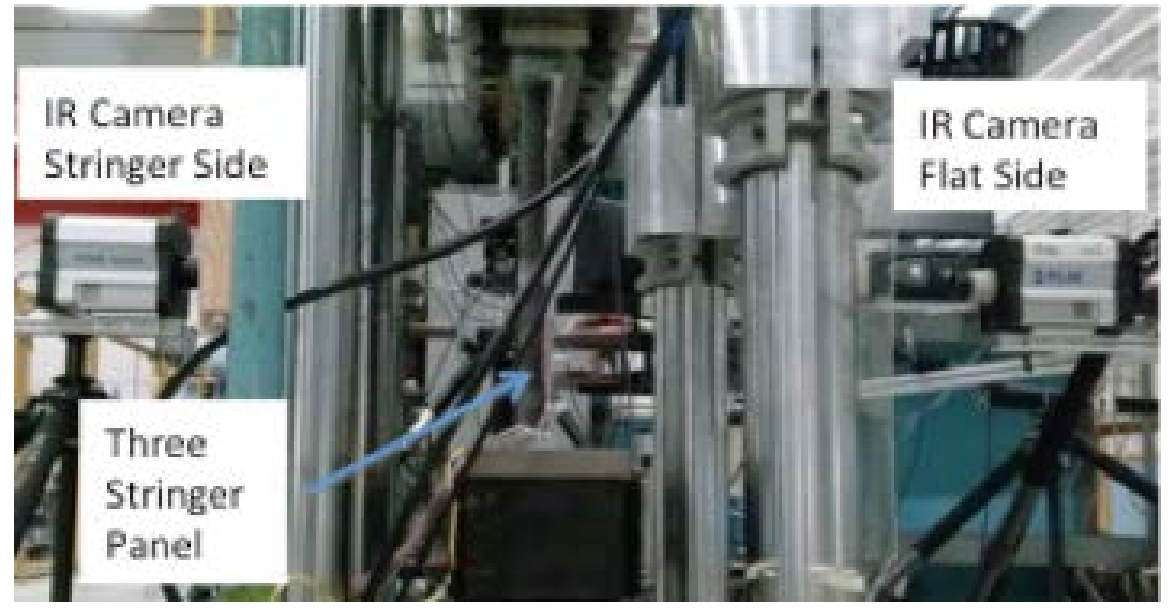

- Passive thermography provides wide area inspection of a composite structure during load testing to monitor damage growth and determine when to stop the fatigue loading.

- Most prior efforts have focused on responses that occurs at the same frequency as the cyclic loading

- At some points there is a significant signal at twice the frequencythe phase of these points fall in a relatively small range 


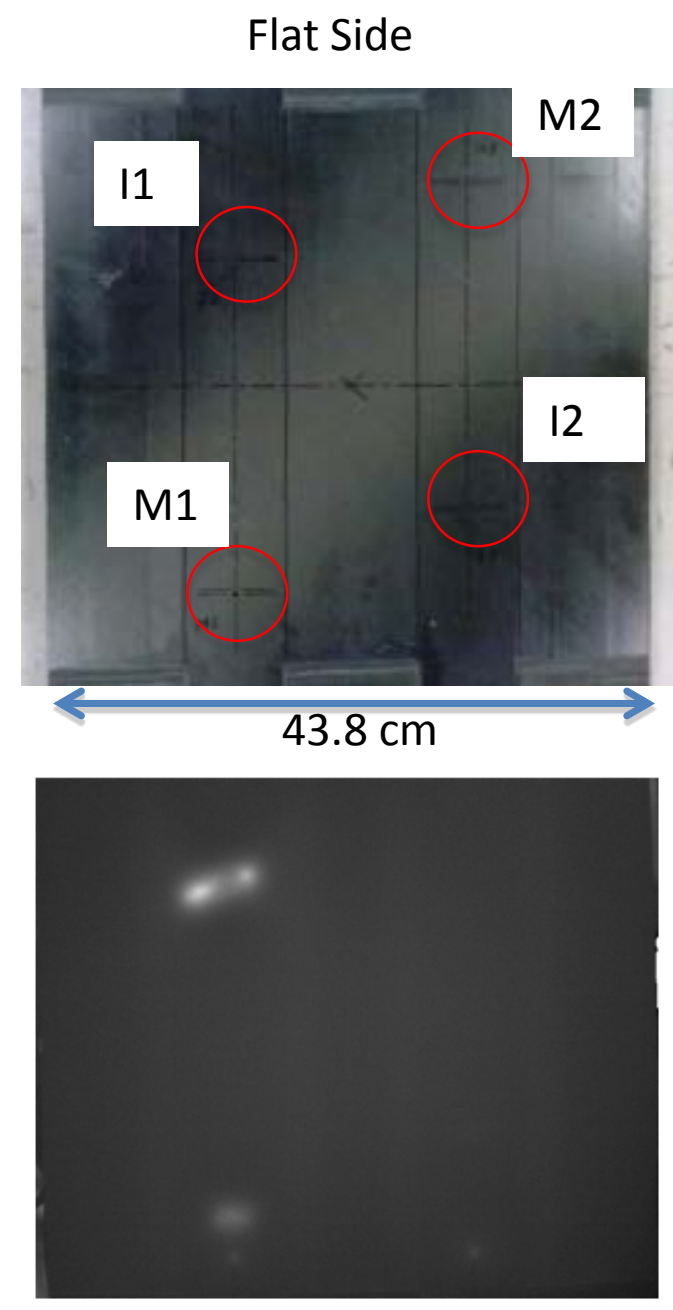

$98.6 \%$ of Life
$31.6 \%$ of Life
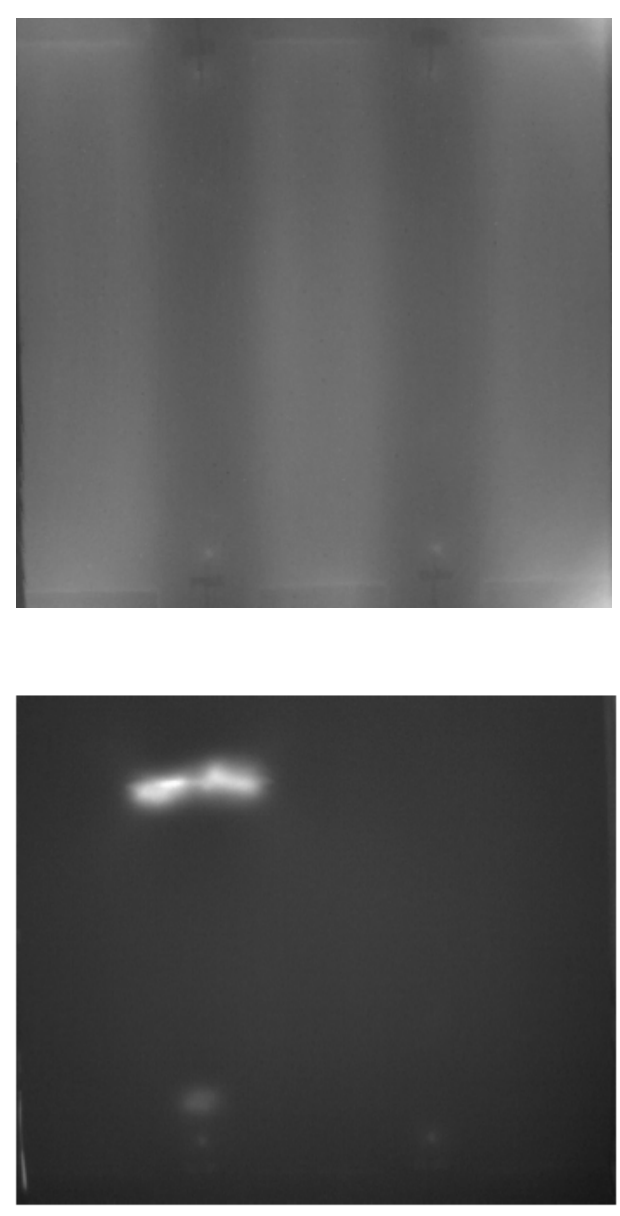

$99.2 \%$ of Life
$97.3 \%$ of Life
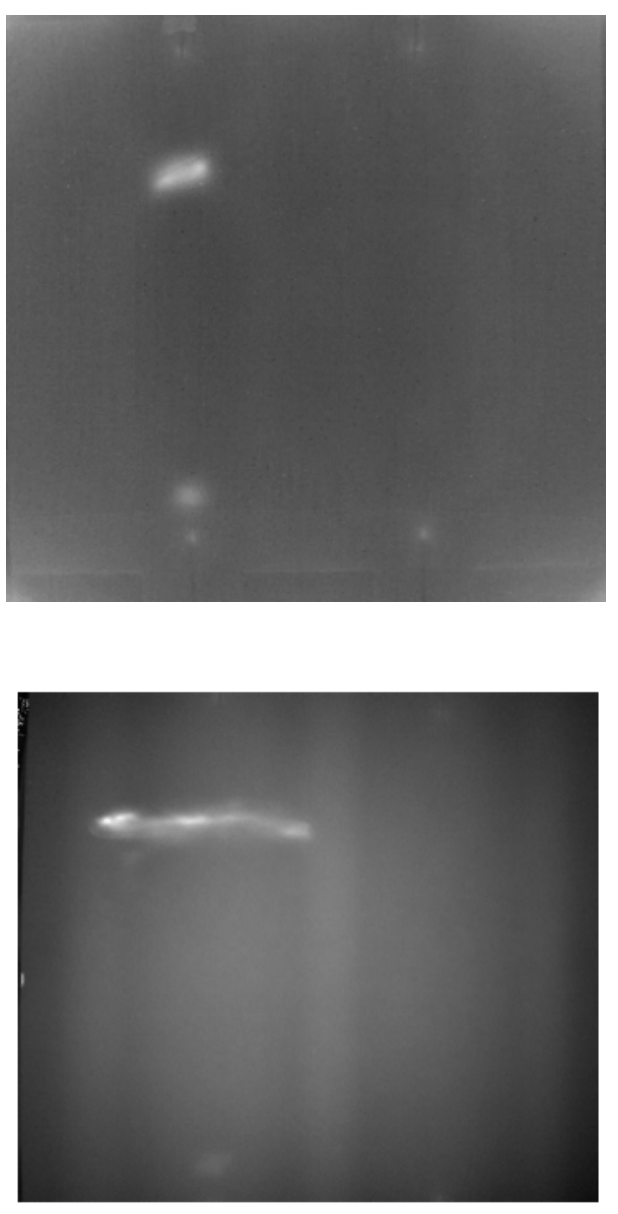

$99.9 \%$ of Life 


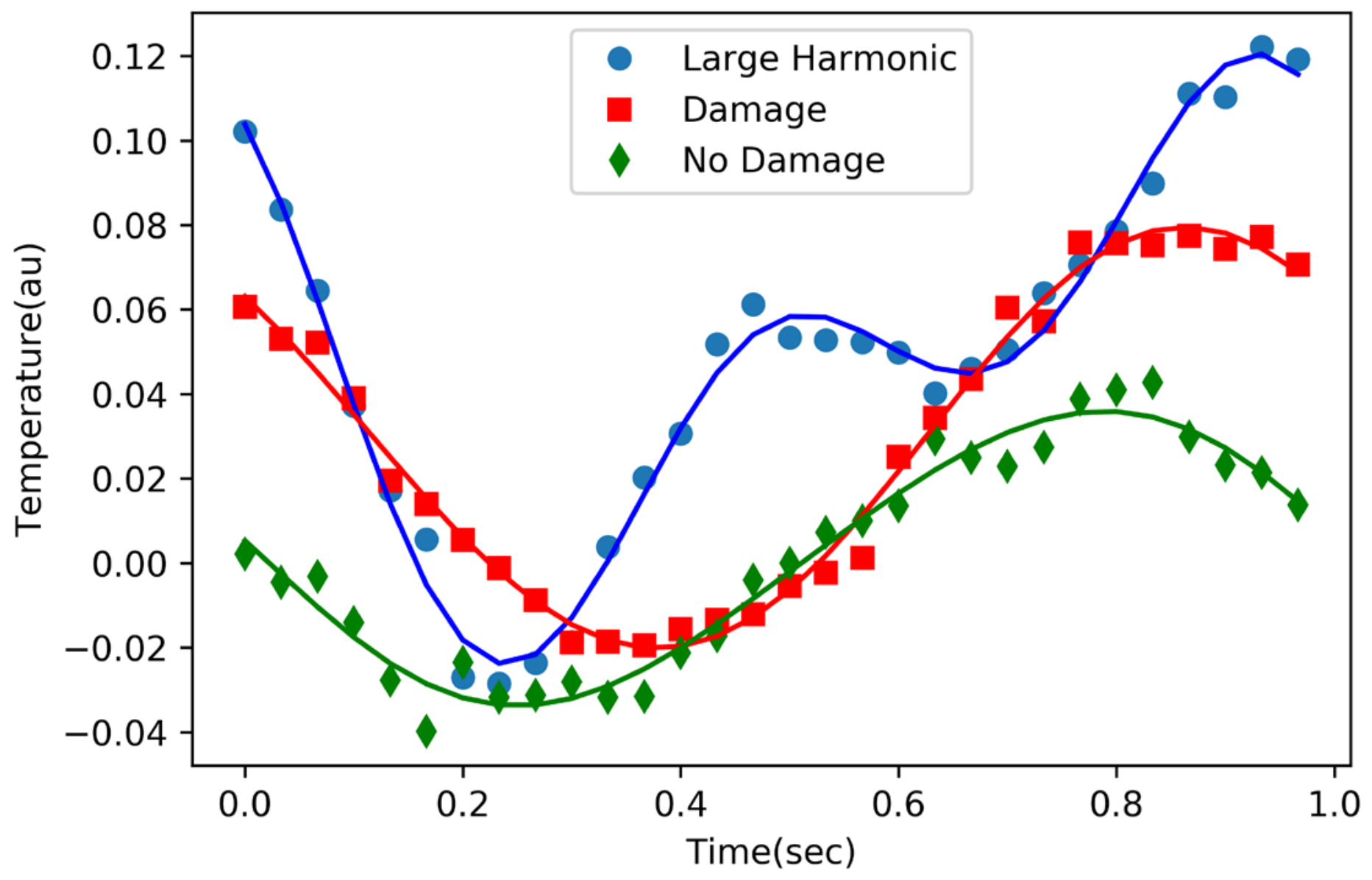

Solid Lines are fits of responses with:

$T(t)=a_{0}+a_{1} t+a_{2} \cos (\omega t)+a_{3} \sin (\omega t)+a_{4} \cos (2 \omega t)+a_{5} \sin (2 \omega t)$ $\omega=4 \pi / \mathrm{sec}$ 


\section{Thermography Maps}

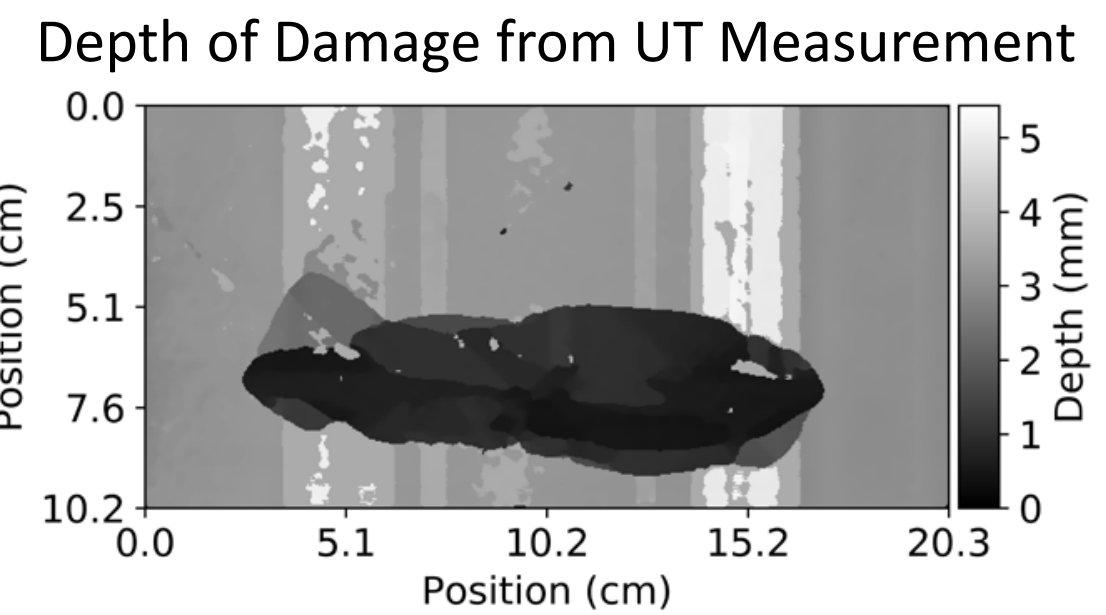

Amplitude of Passive Thermography Fundamental

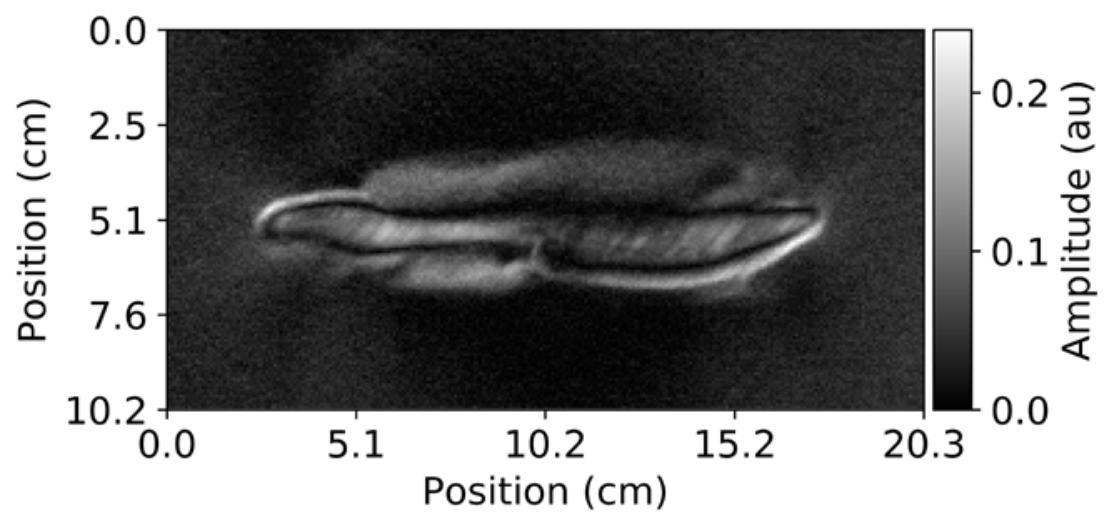

Amplitude of Passive Thermography Harmonic

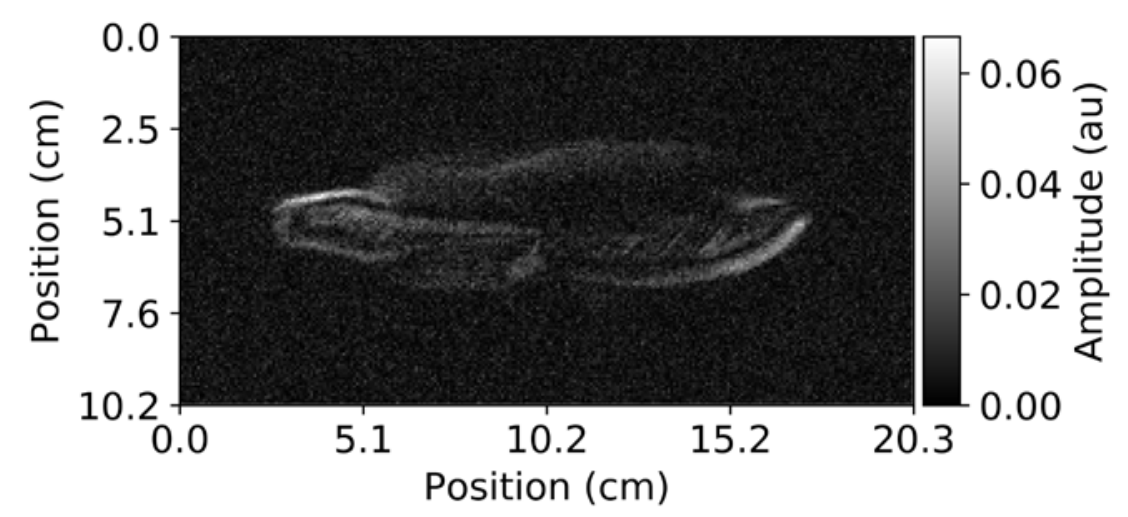




\section{Thermography Harmonic Amplitudes}




\section{Responses}

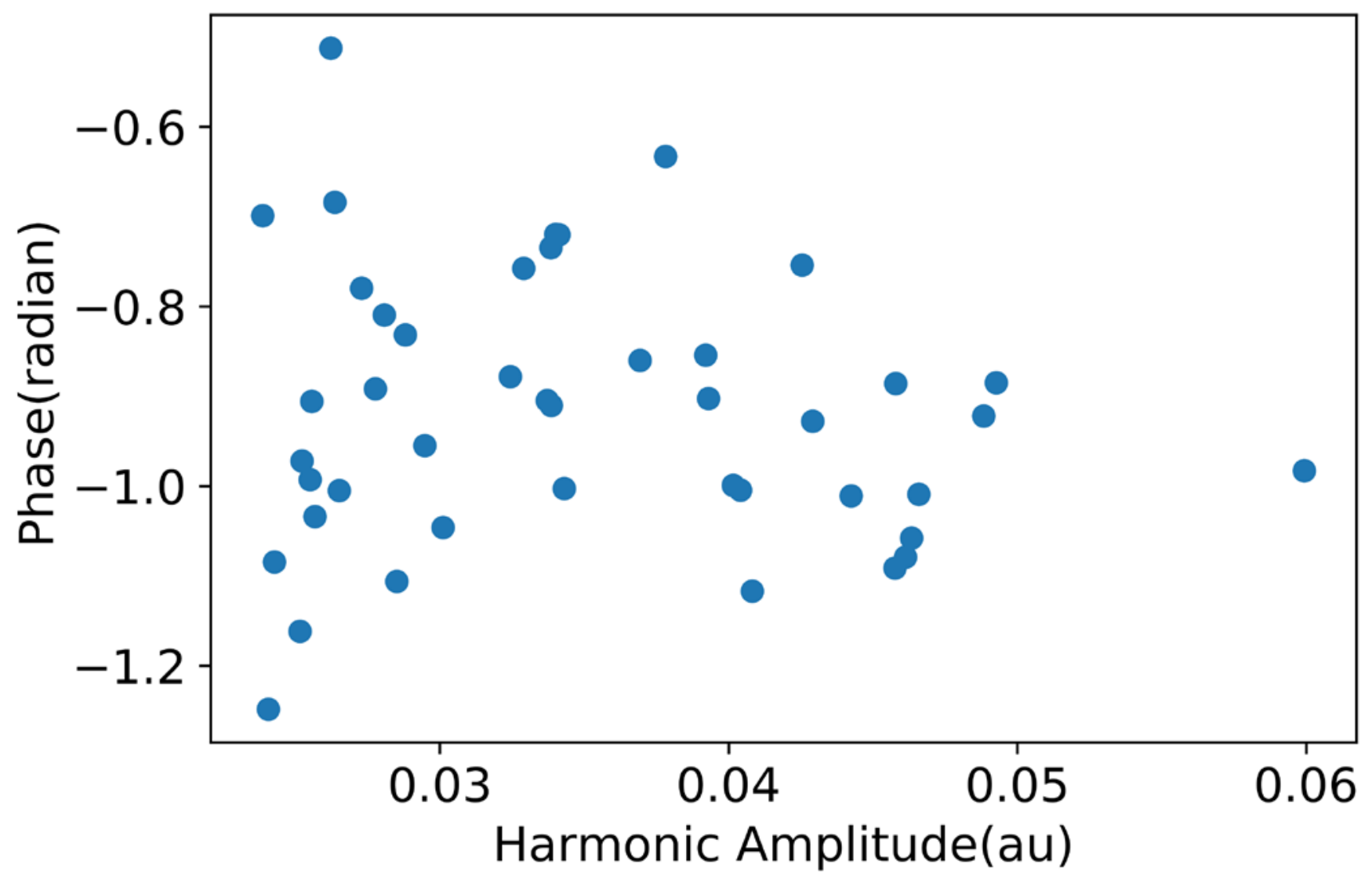

Average phase $=-0.90 \mathrm{rad}$

Standard Deviation $=0.15 \mathrm{rad}$ 


\section{Simple Friction Source}

NASA Langley Research Directorate

- Focus is determining the phase

- Power expended in moving object against force $P=\bar{F} \cdot \bar{v}$ where $v$ is the velocity

- $v$ is relative movement of two surfaces of a delamination

- Assume amplitude of $\bar{F}$ is constant

- Relative displacement of surfaces is proportional to $\sin (\omega t)$

- Magnitude of velocity proportional to $|\cos (\omega t)|$

- Power proportional to $|\cos (\omega t)|$ 


\section{One-Dimensional Model with}

\section{Subsurface Source}

$v(0, s), f(0, s)=0$

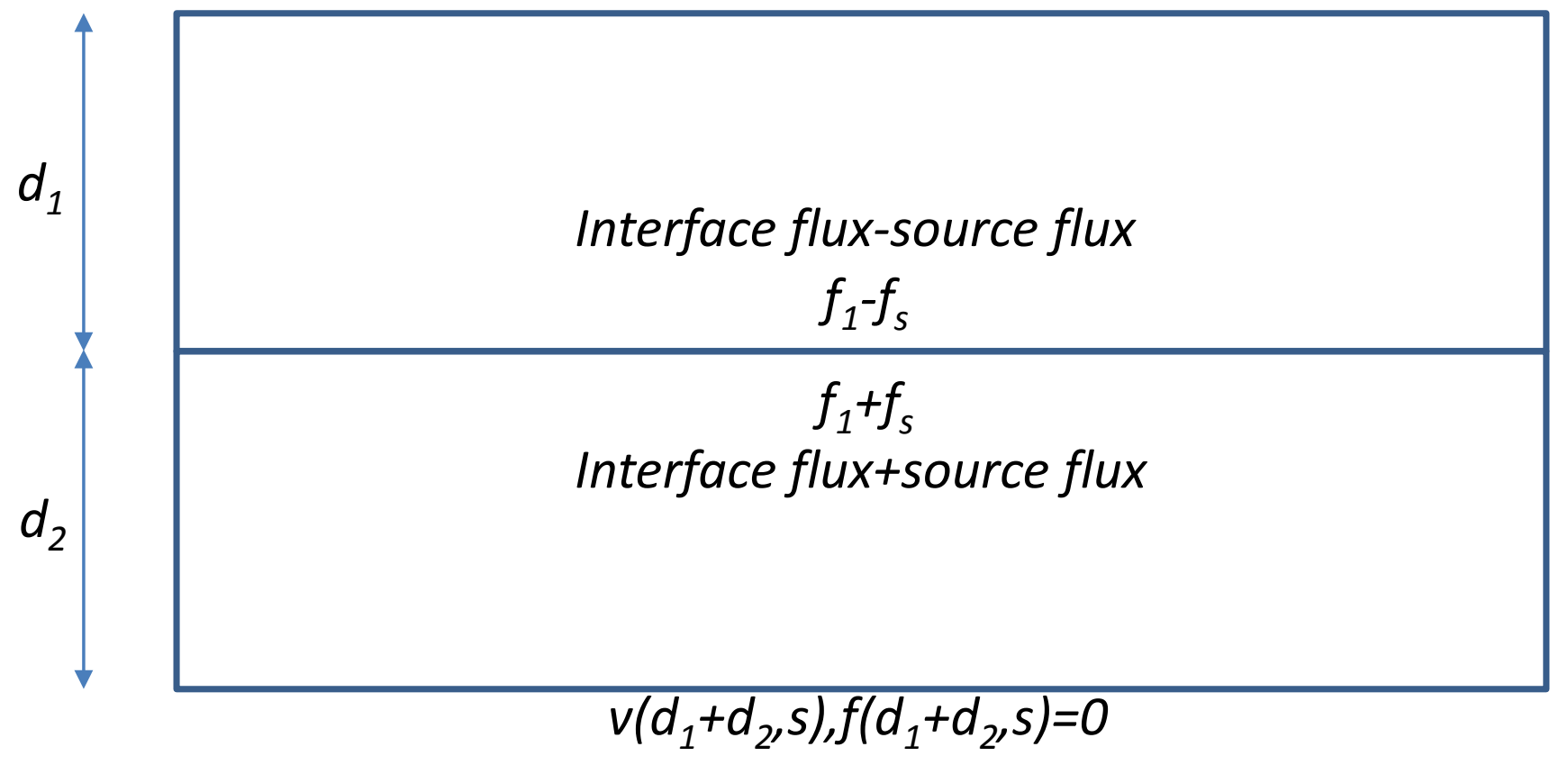

- Interface flux is the result of a temperature gradient at the interface and needs to be solved for

- Source flux, $f_{s}$, is from heat generated at the interface, $f_{s}=C|\cos (\omega \mathrm{t})|$

- Series solution is possible (details in paper) 


\section{Series Solution for $\mathrm{P}|\cos (\omega \mathrm{t})|$ Source at Different Depths Below Surface}

NASA Langley Research Directorate

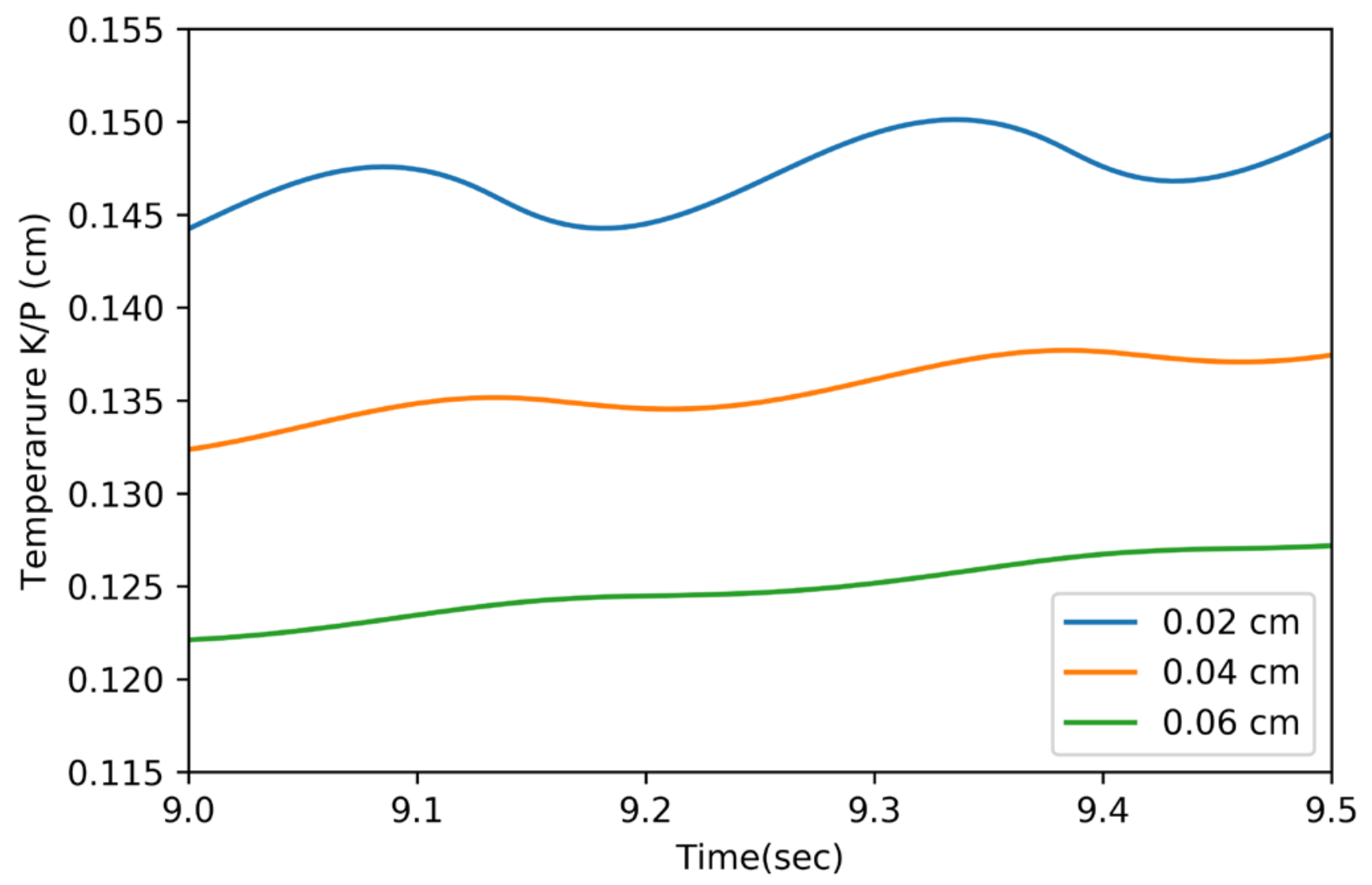

Block thickness is $0.32 \mathrm{~cm}$, Diffusivity $=0.00425 \mathrm{~cm}^{2} / \mathrm{sec}$, Frequency $=2 \mathrm{~Hz}$ 


\section{Amplitude and Phase for Different Depth Sources}

\section{NASA Langley Research Directorate}

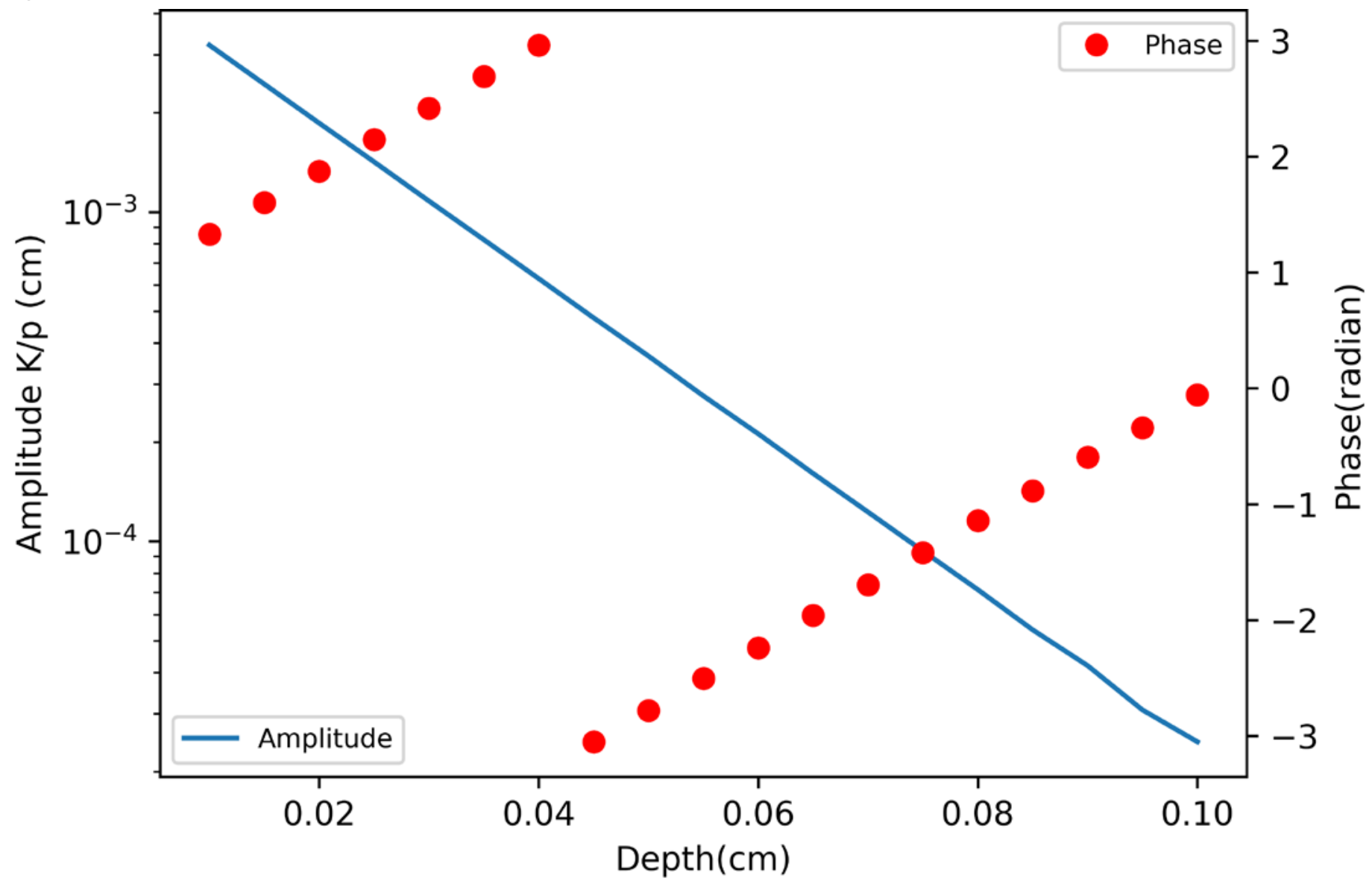

Source $p|\cos (\omega t)|$ at different depths in $0.32 \mathrm{~cm}$ thick block, Diffusivity $=0.0045 \mathrm{~cm}^{2} / \mathrm{sec}$

Phase is approximately linearly dependent on source depth

Estimate of depth of harmonic source based on phase $-0.084 \pm 0.003 \mathrm{~cm}$ 


\section{Two-Dimensional Model with Subsurface Source}

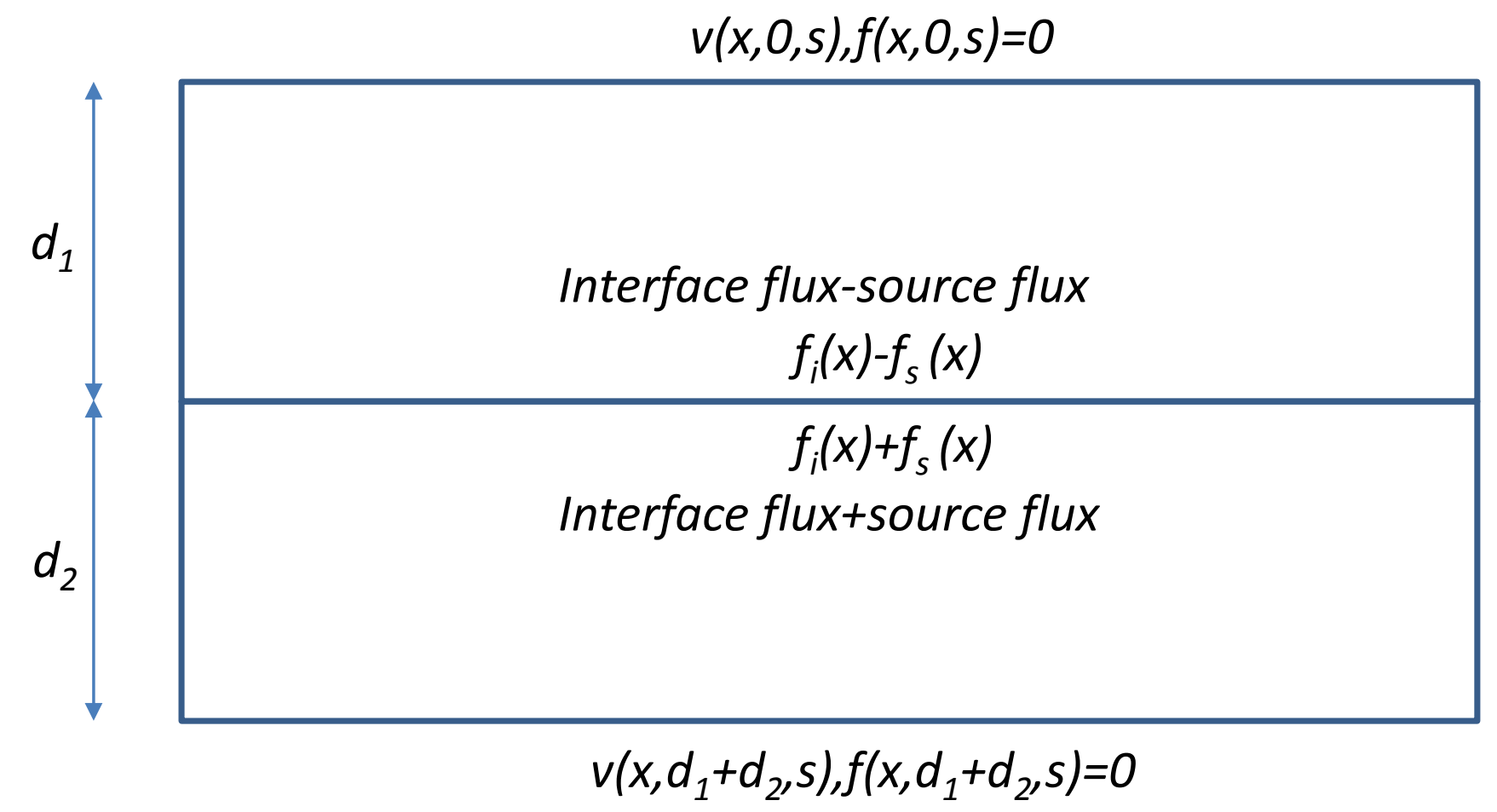

- $v(x, 0, s)$ found for using quadrupole method (details in paper)

- Source flux $f_{s}(x)$, is spatial variation in the heat source at the interface

- Assume $f_{i}(x)=P|\cos (\omega t)| \delta\left(x-x_{0}\right)$ - Point source 2D (Line Source 3D) 


\section{Line Source Response for $P|\cos (\omega t)|$ Source at Different Depths Below Surface}

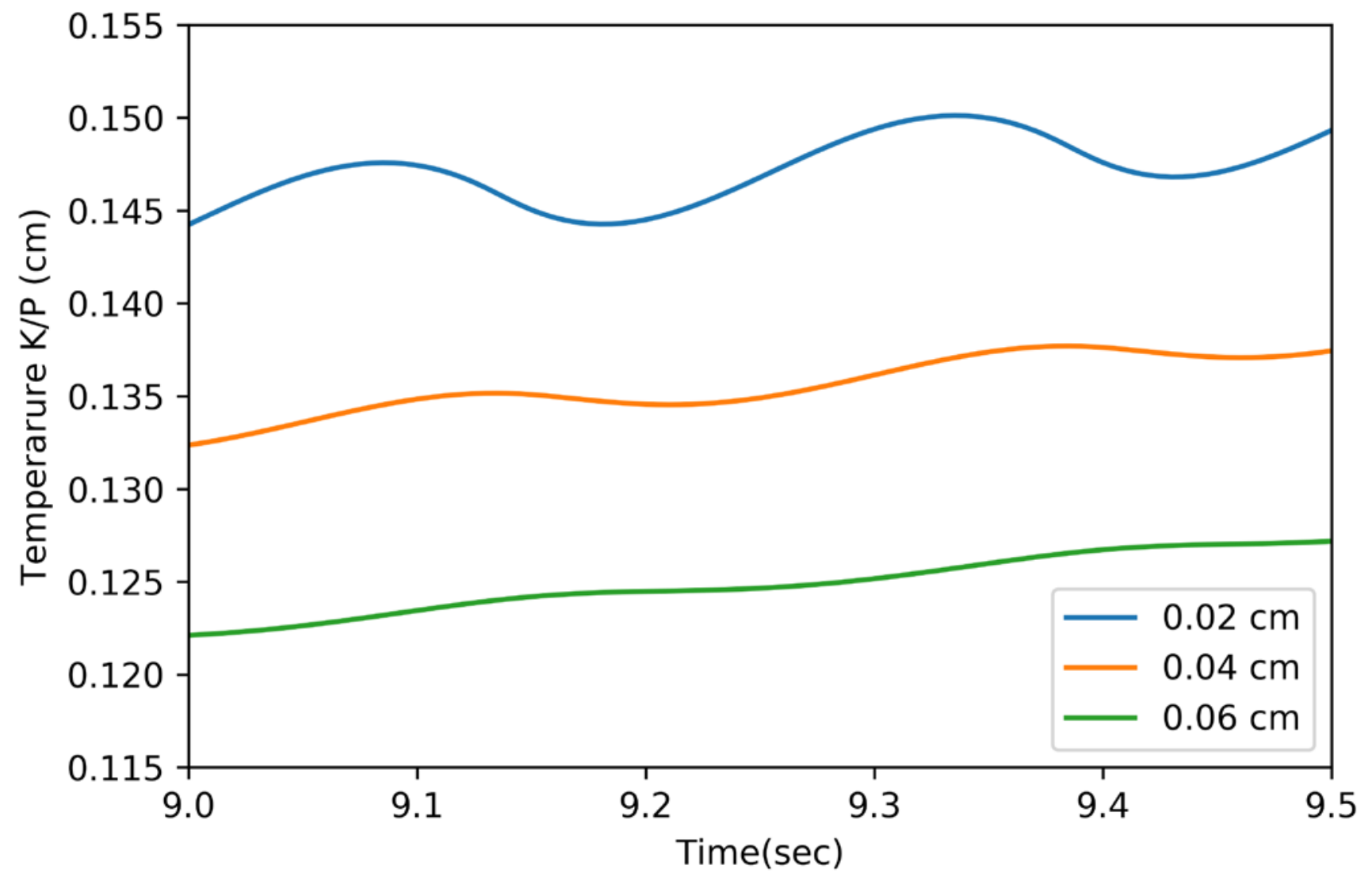

Block thickness is $0.32 \mathrm{~cm}$, Diffusivity $=0.0045 \mathrm{~cm}^{2} / \mathrm{sec}$, Frequency $=2 \mathrm{~Hz}$ Amplitudes significantly less than for planar source (1D solution) Phase is approximately the same 


\section{Simulation Responses}

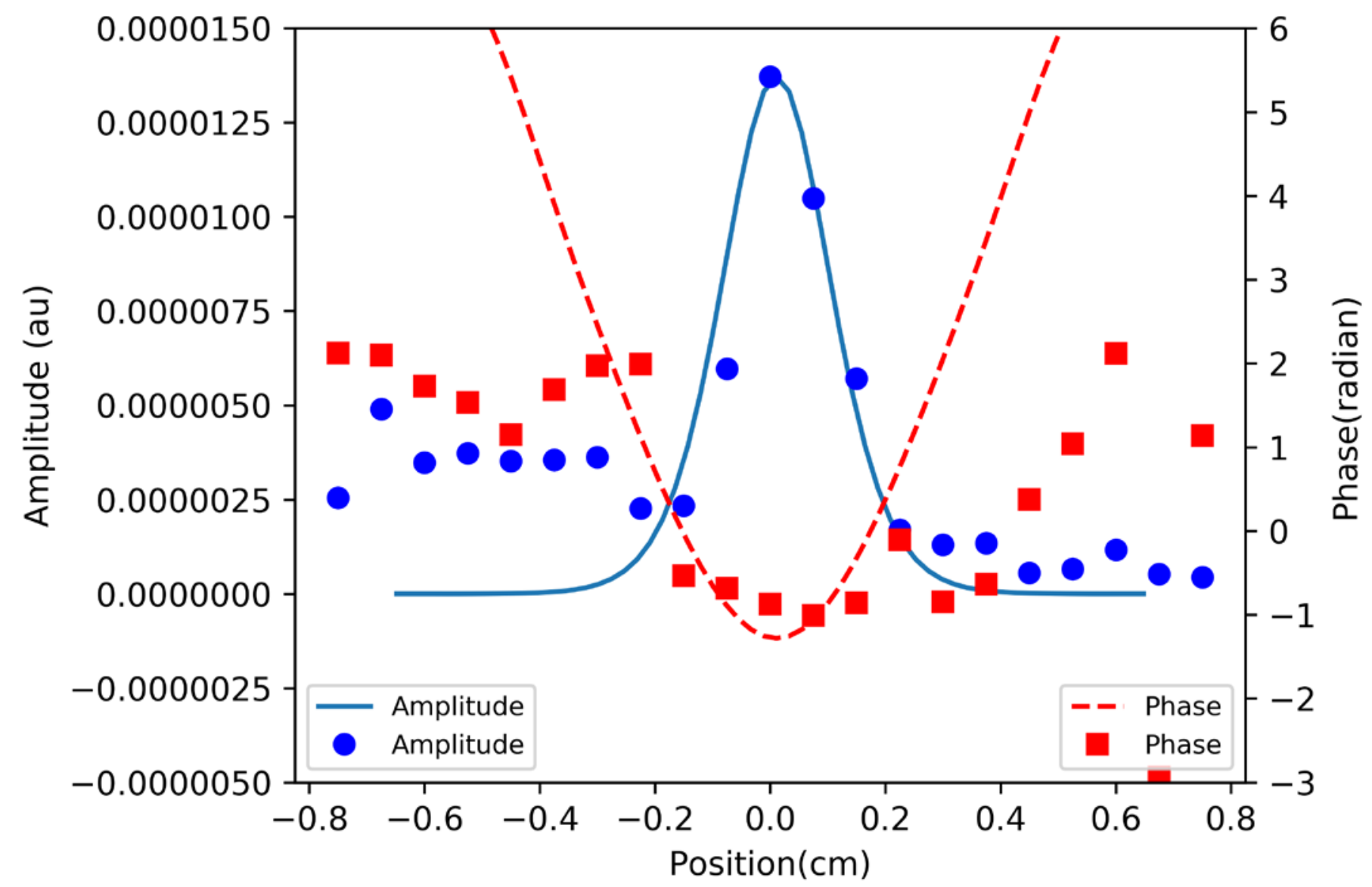

Simulation Parameters - Block thickness is $0.32 \mathrm{~cm}$, Source Depth $-0.085 \mathrm{~cm}$ Surface Normal Diffusivity $=0.0045 \mathrm{~cm}^{2} / \mathrm{sec}$, In-plane Diffusivity $0.025 \mathrm{~cm}^{2} / \mathrm{sec}$ Frequency $=2 \mathrm{~Hz}$ 


\section{Summary}

NASA Langley Research Directorate

- Passive thermography has a significant harmonic at distinct locations near edges of subsurface delamination.

- Phases of all significant harmonic responses are approximately the same.

- From one-dimensional series solution assuming a simple friction source, an estimation of a source depth is $0.084 \mathrm{~cm}$, which is in reasonable agreement with ultrasonic measurements $(0.06 \mathrm{~cm})$.

- A two-dimensional simulation is in reasonably good agreement with spatial variation of both the phase and amplitude of the measured response 